\title{
Water Desalination "The Role of RO and MSF"
}

\author{
Ragvendra Pratap Singh \\ Department Of Chemical Engineering, Jaipur National University, Jaipur(India)
}

\begin{abstract}
This paper provides the overviews of technical way of traditional desalination technique which can be used for water treatment including ways of migrating the impacts of the desalination to the environment and avoiding some of the danger of environment to desalination. Technologies that were originally developed to desalinate water are widely applied in the countries to remove contaminants. Many of the present desalination technologies like distillation, membrane process, ion exchange process etc are used in present contest. Among them membrane separation process is widely used nowadays. This paper suggest the art of the technology which are widely used to desalinate water among which many of them can be used to remove the other contaminants other than salt. It also present the water resources management plant and point out the importance of desalination in order to give the satisfactory result in order to fulfill the increasing water demand. Seawater and waste water from the industries are two important water resources for the desalination plant. Desalination of the sea water accounts worldwide water production of 24.5 million cubic meters per day. Arabian countries use about $45 \%$ of the total production of desalinated water all over the world. The largest desalination plant in south Asia is the Minjur Desalination plant near Chennai in India which produces 36.5 million cubic meter cube of water per year.
\end{abstract}

Keywords: - desalination, distillation, membrane separation, ion exchange.

\section{Introduction}

Desalination refers to any several processes which are mainly concerned for the removal of the some quantity of the salt and other mineral from saline water.

\subsection{Overviews}

Over the previous last few decades, desalination technologies has been used in increasing manner throughout the world to produce the drinking water from the brackish ground and sea water to improve the quality of existing supplies of fresh water for drinking and industrial purposes. In early 1950 there are about 225 land based desalination plants worldwide with a combined capacity of about 27 million galloon par day. There are now about 3500 plants worldwide with the production capacity of about 300 million gallon per day.

1.2 Current scenario of the water desalination technologies in India

- In India 1.1 billion people of whole population do not have quality water. Desalination of sea water and brackish water is one the feasible and identified solution to the current problem of water scarcity.

- Desalination water technology is widely used in water scarce states such as Gujarat, Tamil Nadu, and Rajasthan.

- TamilNadu has maximum number of state government-owned desalination plants in Nochikuppam, Kasimedu and Velachery (area around chennai), Ayodhyakuppam, Narippaiyur ,Ramanathapuram (45 plants ), Rameshwaram and Kalpakkam. New plants are coming at Karaikal, Tuticorin, Nemili and Minjur.

- Indian government has doing work for municipal and industrial desalination plants at Barmer, Jaisalmer, Bharatpur, Jaipur, Jalore and Sirohi in Rajasthan.

- There are around 1000 desalination plants functional in India and the current total capacity stands at about 291,820 cubic meters per day.

\subsection{Current scenario of the water desalination technologies in world}

- It can be seen that the scarcity of water had been spread widely in the Asian country in the year of 2000 .

- In upcoming 25 years the problem of scarcity of water will spread in the various part of the India and China.

- It is predicted that in coming 50 years all the ground water present in Singapore will be depleted which may threat not only for the Singapore but also for all countries of the world. 


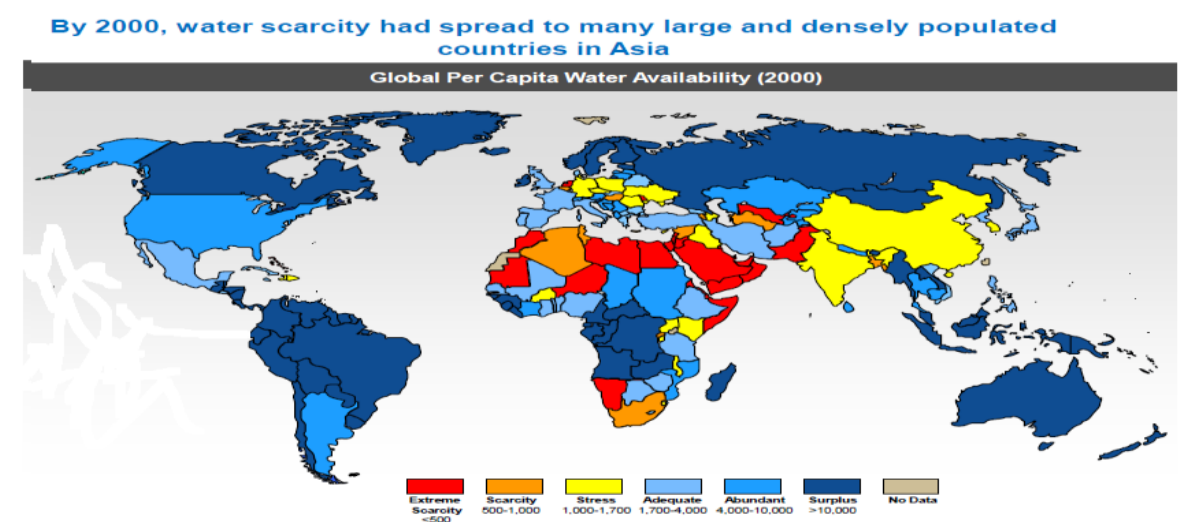

Source:- Ministry of water Resources, India

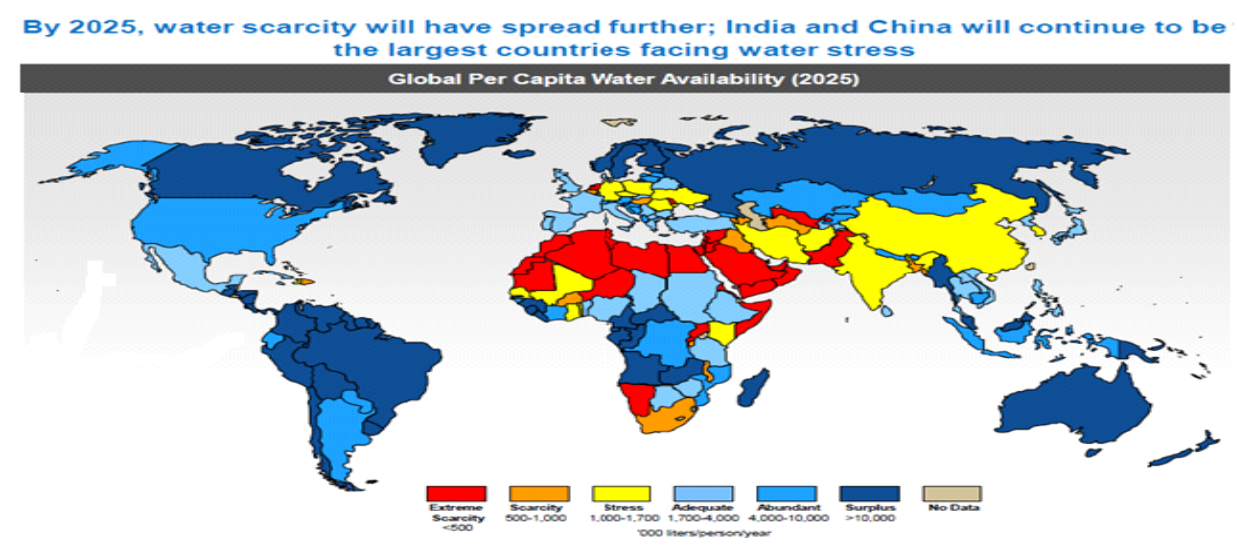

Source:- Ministry of water resources.

\subsection{Future water supply and its need}

A comparison of past analysis of water use indicates that both water withdrawals and water consumption in world gradually increases. The demand for water will probably continue to increase in the future. Dams and other water divergence are becoming more expensive and time consuming to construct and often meet with the potential environmental impacts.

\subsection{Desalination processes}

\section{Desalination Technologies}

The major processes for desalination used worldwide are:-

- Thermal processes

$>$ Multistage Flash Distillation.

$>$ Multiple Effect Distillation.

> Vapour Compression Distillation.

- Membrane processes

$>$ Reverse Osmosis

$>$ Electro-dialysis

Mostly the production of fresh water in India is done by multistage flash distillation and reverse osmosis.

\subsubsection{Multi Stage Flash Distillation}

It is the type of the thermal desalination technology and is the oldest but still being constructed. It is mainly suitable for the cogeneration. Between 25 and 65 percent of the feed water is recovered by most MSF plant.

\subsubsection{Reverse Osmosis}

It is the newest and most applicable type of the membrane and electrical technology, now being scaled to relatively large plant, but still smaller than MSF. Brackish water RO plants typically recover 50 to 80 percent of the feed water, with 90 to 98 percent salt rejection. For seawater, recovery rates vary from 20 to 40 percent, with 90 to 98 percent salt rejection. 


\subsection{Cost comparison of freshwater production from seawater for MSF and RO}

Cost is a primary factor in selecting a particular desalination technique for water treatment. Desalination costs have decreased markedly in the last few decades.

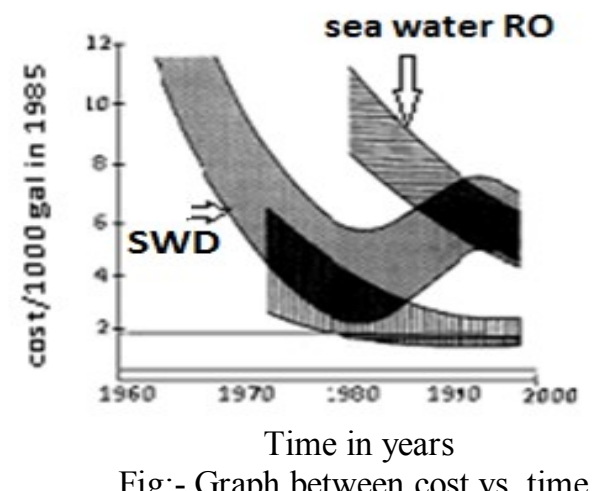

It is important to recognize that the desalination costs vary significantly depending on :

- The size and the type of desalinating plant.

- Plant location

- $\quad$ Feed water quality

- Waste concrete disposal costs

- $\quad$ Energy cost, financial cost and reliability of the plant.

for MSF

For RO
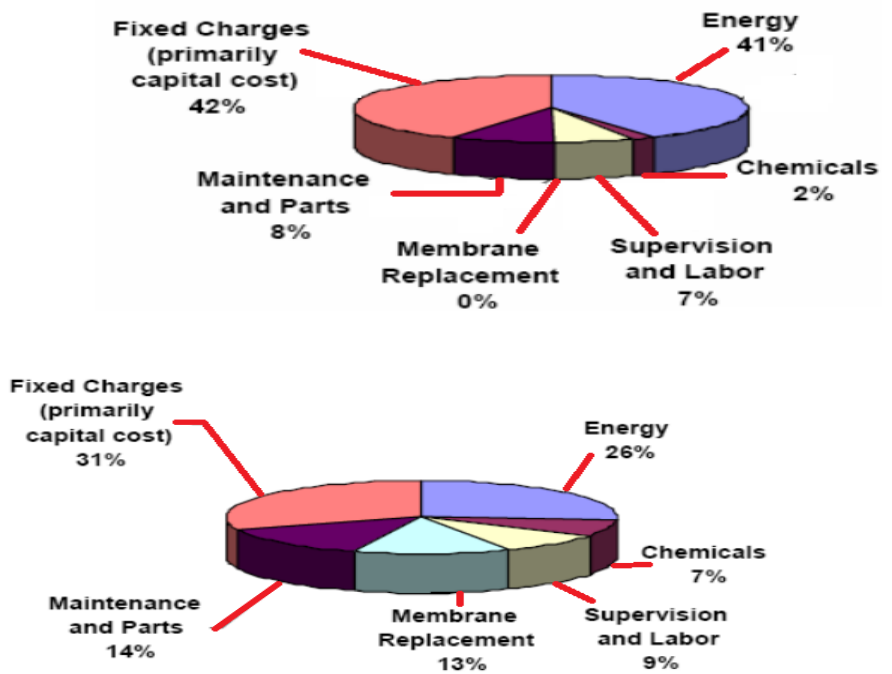

Source:- Ebensperger and Phyllis Isley

\subsection{Economics of MSF and RO}

\begin{tabular}{|l|c|c|}
\hline & MSF & RO \\
\hline $\begin{array}{l}\text { Specific } \\
\text { Investment Cost } \\
{\left[\$ / \mathrm{m}^{3} / \text { day] }\right.}\end{array}$ & $1,200-1,500$ & $700-900$ \\
\hline $\begin{array}{l}\text { Total Cost } \\
\text { Product }\left[\$ / \mathrm{m}^{3}\right]\end{array}$ & $1.10-1.25$ & $0.68-0.82$ \\
\hline
\end{tabular}

Source:- Kaufler

\subsection{Drawbacks of RO and MSF}

- $\quad$ Reverse osmosis with its dependence upon high pressure to subvert the normal flow of water requires an energy source and is fairly costly. Similarly distillation with its dependence upon heat to vaporize water also requires energy sources. Though solar power remains an option for the required heat of distillation but is still fairly insufficient and impractical. 
- $\quad$ Both RO and distillation system are extremely wasteful and insufficient, because they use large quantity of water to create a very small amount of purified water. Thus there is still necessary of the new technology.

\subsection{Nuclear Desalination}

Though being highly efficient than that of both RO and MSF, Nuclear Desalination technologies has not been used generally. That is why it is said to be optional treatment process. It is because of the fact that the total capital cost becomes more high as comparison of RO and MSF process. But it is very important to note that if we directly use the waste heat from nuclear power plant to the nuclear desalination plant its cost becomes $33.33 \%$ and $50 \%$ cheaper than that of both RO and MSF respectively.

\subsection{Distribution of desalination technologies in India}
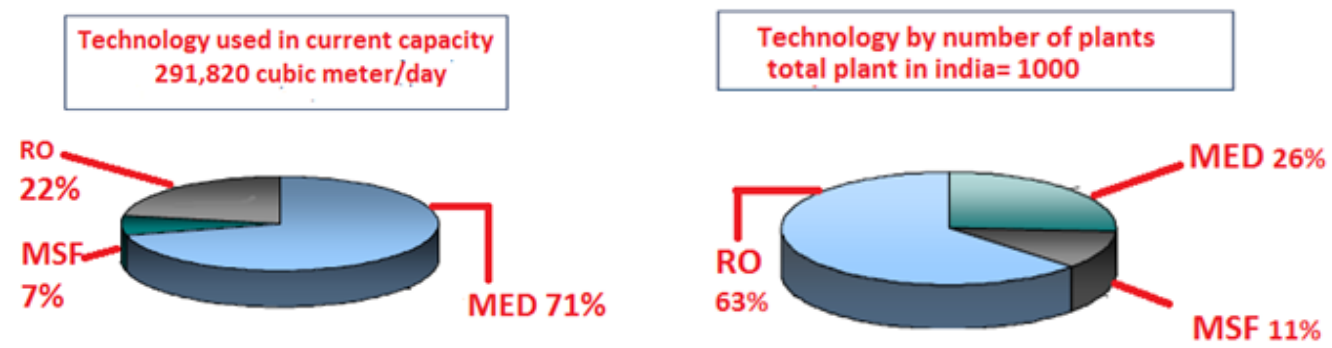

Sources:- Ministry of Water resources, India

- There are around 1,000 desalination plants functional in India whose total capacity stands at about 291,820 cubic meters per day.

- Major Research institutes such as BARC focus on hybrid technology that is a combination of thermal and membrane desalination.

- Currently, most of the plants in India are using RO technology. IDE technologies, Israel implemented MED technology for Reliance India.

\section{Applications}

\subsection{Industrial feed and process water treatment}

According the ministry of water resources, India uses about $6 \%$ of total fresh water abstraction. When talk with the global industrial applications then the industries consumes about $22 \%$ of global fresh water. The high quality water is needed for manufacturing of many industrial products including textiles, leather, paper, pharmaceuticals and other chemicals, beverage and dairy and other food products.

\subsection{Drinking water production}

Drinking water is becoming scare in many coastal areas of India. Desalination technology is the most publicly used for drinking water production in the arid regions like Rajasthan in India. About $20 \%$ of drinking water production in India in the year of 2010 is done by the desalination. World widely 1.7 billion per day of pure drinking water is produced.

\subsection{Water availability in areas of drought}

\section{Advantages}

Main purpose of desalination is to make water available in those areas that have limited resources of fresh water. As of march 2009, Minjur plant of water desalination is the largest plant in Asia ( Rs. 600 crores plant) the plant can process and supply 100 million liters of water per day.

\subsection{Alternative sources of water in arid regions}

Desalination provides a readily available and reliable alternative source of water in times of several droughts.

\subsection{Intake}

\section{Environmental Impacts}

In India the Clean Water Act (CWA) was created to "restore and maintain the chemical, physical, and biological integrity of the nation's water." Recognizing the hazards of pollution and the threat that unclean water posed to public health and welfare, Congress enacted the Federal Water Pollution Control Act (FWPCA) in 1948 to "establish a national policy for the prevention, control and abatement of water pollution." 


\subsection{Outtake}

\subsubsection{Waste disposal}

The chemicals used in desalination like Chlorine, hydrogen chloride, hydrogen peroxide once they lost their ability to clean water; these chemicals are dumped, which becomes a environmental concern. These chemical often find their way back to the ocean, where they poison plant and animals life.

\subsubsection{Ocean population}

Organism most commonly affected by brine and chemicals discharge from desalination plants are " plankton and phytoplankton ", which produces the base of all marine life by forming the base of food chain so have the ability to negatively affect the population of animal in the ocean.

\section{Conclusions}

Conventional desalination technologies that are distillation and membrane based, rely on RO and MSF, followed by MED as it is steadily gaining popularity. Distillation technologies that are often coupled with power plants to increase the overall efficiency of the plant and reduce the cost and their usage is very common in the Middle East. The selection of a particular desalination technology involves many factors, such as economics, environmental impact, energy requirement, and dependence on feed water quality. Finally, it must be realized that desalination is one part of the solution. Only a synergistic approach involving desalination, water management, consumption reduction and water reuse can efficiently confront the water challenge.

\section{Acknowledgement}

Highly acknowledged by the Department of chemical engineering "Jaipur National University" to allow me for doing the project on the topic of desalination and also the support of the department.

\section{References}

[1] R. Einav, k. Harussi, H. Perry, The footprint of desalination processes on the environment, Desalination 152 (1-3) (2003) 141-154.

[2] Toufic Mezher; Hassan Fath; Abbas, Zeina Khaled Arslan, Techno-economic assessment and environmentalimpacts of Desalination Technologies, Desalination 266 (2011) 263-273, august 2010.

[3] Frost and Sullivan, Assessment Of Indian Desalination Market, Water Without A Pinch Of Salt, 498 Anna Sulai Chennai, July 2009.

[4] Lattemann Sabine, Hopner Thomas, Environmental impact and impact assessment of sea water desalination, Desalination 220 (2008) 1-15, University Of Oldenburg, Germany, March 2007.

[5] Warne E William; Rozelle Lee; Taylor S. James, Using Desalination Technologies For water Treatment, OTAProject, NTIS order \#pb88-193354, March 1988.

[6] K.V. Reddy, N. Ghaffour, Overview of the cost of desalinated water and costing methodologies, Desalination 205 (1-3) (2007) 340-353.

[7] Camacho Mar Lucy, Dumee Ludovic, Jang Jianhua, Li Jun-de, Duke Mikel, Gomez Juan, Gray Stephan, Advances in water distillation for water desalination and purification action, Water 2013, 5(1), 94-196, January 2013.

[8] A. Almulla, A. Hamad, M. Gadalla, Integrating hybrid systems with existing thermal Desalination plants, Desalination 174 (2) (2005) 171-192. 